Л.И.Волкова ${ }^{1}$, Ю.М.Падеров ${ }^{2}$, Л.Р.Вильданова ${ }^{3}$

\title{
Остеохондропластическая трахеобронхопатия: клинико- морфологическое наблюдение
}

1 - Сибирский государственный медицинский университет;

2 - Областная клиническая больница, Томск

\section{L.I.Volkova, Yu.M.Paderov, L.R.Vildanova \\ Osteochondroplastic tracheobronchopathy: clinical and morphological features. Case report}

Несмотря на появление целого ряда обзорных и описательных публикаций, посвященных остеохондропластической трахеобронхопатии (ОХТ) [1-5], данная патология по-прежнему является скорее случайной диагностической находкой, обнаруживаемой в результате исследования бронхобиоптатов, либо при проведении компьютерной томографии органов грудной клетки. Субъективной причиной этого, на наш взгляд, является не только позднее развитие клинических симптомов заболевания, но и редкость его прижизненного выявления, которая в большей мере обусловлена слабым знакомством с данной патологией врачей общеклинической сети и специалистов функциональной диагностики, что приводит к тому, что в значительном проценте случаев диагноз ОХТ выставляется посмертно, по результатам аутопсии. Между тем, по мнению ряда исследователей [2], ОХТ вовсе не является казуистической патологией и встречается гораздо чаще, чем 3 случая на 1000 аутопсий [5]. Все это диктует необходимость дальнейшего накопления и обобщения клинико-морфологических сведений о проявлениях данного заболевания.

Приводим наше наблюдение.

Больная В. 43 лет, сельская жительница, поступила в ревматологическое отделение ОКБ 15.11.02 на обследование с диагнозом системное заболевание соединительной ткани. Предъявляла жалобы на одышку смешанного характера при минимальной физической нагрузке, ощущение онемения и холода в пальцах рук и ног, вечернее повышение температуры тела до $38{ }^{\circ} \mathrm{C}$, резкую слабость. Считает себя больной в течение года, когда впервые стала отмечать одышку, вначале выраженную при небольшой физической нагрузке, ходьбе, а затем и в покое. В феврале 2001 г. по этому поводу обследовалась у пульмонолога и кардиолога ОКБ, выставлен диагноз обострение хронического обструктивного бронхита На рентгенограмме органов грудной клетки в феврале 2001 г.: корни структурны, легочный рисунок в прикорневых зонах и нижних легочных полях с обеих сторон усилен, локально деформирован и обогащен. Проведено лечение (ципролетом, теопеком, халиксолом), после которого отмечалось незначительное улучшение. В июле у больной вновь усилилась одышка, температура повысилась до субфебрильных цифр. После назначения вышеуказанные препаратов улучшения самочувствия не было отмечено. В сентябре больная повторно проконсультирована у пульмонолога ОКБ, ей выставлен диагноз бронхиальная астма и назначен будесонид в суточной дозе 600 мкг. В октябре-ноябре во время приема будесонида больная наблюдалась у терапевта районной больницы, кото- рым и была направлена на стационарное лечение в связи с отсутствием эффекта от проводимой терапии и нарастанием одышки.

При поступлении в стационар состояние больной средней степени тяжести. Цианоз губ, одышка в покое, ЧД - 24 в 1 мин. При перкуссии над легкими звук легочный, дыхание жесткое, хрипов нет. Границы сердца в норме, ритм правильный, ЧСС - 90 в мин., усиление 2-го тона на легочной артерии, АД - 120 / 80 мм рт. ст. В вечерние часы отмечено повышение температуры тела до $37,8-38,2{ }^{\circ} \mathrm{C}$.

Анализ крови: Нв - 111 г / л, лейкоциты - 12,1 × 109 / л, палочкоядерные $-10 \%$, сегментоядерные $-67 \%$, эозинофилы $1 \%$, моноциты $-8 \%$, лимфоциты $-14 \%$, СОЭ - 60 мм / ч. Анализ на Le-клетки отрицательный.

Рентгенограмма органов грудной клетки: диффузный пневмофиброз. Компьютерная томография органов грудной клетки: признаки диссеминированного поражения легких, лимфаденопатия. Необходимо дифференцировать заболевания с диссеминированным туберкулезом, саркоидозом, метастазами в легкие и лимфоузлы. ЭхоКГ: незначительное расширение полости правого желудочка. ЭКГ: синусовая тахикардия, 115 в мин, отклонение электрической оси сердца вправо, признаки перегрузки правого желудочка.

Проводился дифференциальный диагноз между системным васкулитом, фиброзирующим альвеолитом, туберкулезом легких, метастазами в легкие. Планировавшиеся для верификации диагноза бронхоскопия, биопсия легкого, спирография были отложены из-за тяжести состояния больной.

Лечение: эуфиллин $2,4 \%-10,0$ в/в, дексаметазон -4 мг в/в, ампициллин -2 млн ед. / сут. в/м, верапамил -120 мг / сут., оКсигенотерапия.

На фоне проводимой терапии состояние больной ухудшилось, нарастала одышка, в связи с чем 20.11.02 пациентка была переведена в отделение анестезиологии и реанимации, где в этот же день на фоне нарастающей дыхательной недостаточности наступила смерть больной.

\section{Заключительный клинический диагноз}

Основное заболевание: диссеминированный туберкулез легких.

Осложнения болезни: дыхательная недостаточность III ст.; легочное сердце в стадии декомпенсации.

На вскрытии: труп женщины правильного телосложения, умеренного питания. Грудная клетка цилиндрической формы. Плевра гладкая, блестящая, прозрачная. Просвет трахеи сужен: периметр $-3,5$ см. Слизистая трахеи на всем протяжении, кроме задней поверхности, вне хрящевого полукольца, слизистая главных, долевых и частично сегментарных бронхов замещена округлыми, линейными или неправильной формы участками костной ткани, выбухающими в просвет до 2-3 мм. Стенки бронхов утолщены, выступают над поверхностью среза, в просвете их - небольшое количество прозрачной жидкой слизи. Легкие тестоватой консистенции, пестрой окраски за счет чередования бледно окрашенных, почти белых, и ярко-красных участков. С поверхности среза при надавливании отделяется небольшое количество пенистой прозрачной жидкости. Все группы внутригрудных лим- 
фоузлов увеличены до 0,5-1 см, образуют "цепочки" и "пакеты". Сердце - 340 г. Перикард, клапанный, пристеночный и хордальный эндокард не изменены. Толщина миокарда левого желудочка -1 см, правого $-0,8$ см. Длина приносящего тракта правого желудочка $-8,2$ см, выносящего $-8,5$ см. Миокард дряблый, красно-коричневого цвета. На интиме коронарных артерий липидные пятна. В печени (1 400 г) выражен мускатный рисунок. В полости желчного пузыря - большое количество конкрементов с фассетированной поверхностью.

При гистологическом исследовании в трахее, главных и долевых бронхах отмечаются очаговая атрофия слизистой оболочки и очаговая плоскоклеточная метаплазия. В собственной пластинке слизистой и подслизистой основе - разнокалиберные кальцинаты и островки новообразованной костной ткани (рисунок). Хрящевая ткань с дистрофическими изменениями, участками оссификации, негустой диффузной лимфоидной инфильтрацией. В долевых бронхах выражена гипертрофия мышечного слоя. В мелких бронхах - очаговая атрофия слизистой, гипертрофия гладкомышечного слоя, диффузная лимфоидная инфильтрация стенок. В легких наряду с участками дистелектазов встречаются комплексы эмфизематозно расширенных альвеол. Стенки межальвеолярных перегородок утолщены за счет склероза, густо инфильтрированы лимфоцитами и сегментоядерными лейкоцитами. В просвете единичных альвеол обнаруживается эозинофильная жидкость с примесью лейкоцитов, альвеолоцитов и сидерофагов. Имеет место выраженный диффузно-очаговый пневмосклероз с умеренной лимфогистиоцитарной инфильтрацией. Интраорганные сосуды полнокровны, со значительно утолщенными за счет гипертрофии мышечных волокон стенками, гиалинозом коллагеновых волокон с накоплением между ними PAS-положительных субстанций. В сегментарных ветвях легочной артерии выявляются атеросклеротические бляшки. Во внутригрудных лимфатических узлах - картина хронического неспецифического лимфаденита.

\section{Патологоанатомический диагноз}

Основное заболевание: остеохондропластическая трахеобронхопатия.

Осложнения болезни: хроническое, преимущественно интерстициальное, воспаление легких с обострением. Выраженный диффузно-очаговый пневмосклероз. Эмфизема легких. Легочная гипертензия (гипертрофия мышечных волокон, гиалиноз коллагеновых волокон, атеросклероз интраорганных артерий легких) Декомпенсированное легочное сердце (гипертрофия правого желудочка $-0,8$ см, вес сердца -340 г), венозное полнокровие печени, почек, селезенки.

Сопутствующие заболевания: камни желчного пузыря.

Причина смерти: острая дыхательная недостаточность.

Особенностью данного случая является распространенное поражение трахеобронхиального дерева с вовлечением в процесс трахеи, главных и долевых бронхов. Деформация и сужение воздухоносных путей привели к развитию бронхообструкции со степенью сужения до 30 \% и легочной гипертензии с
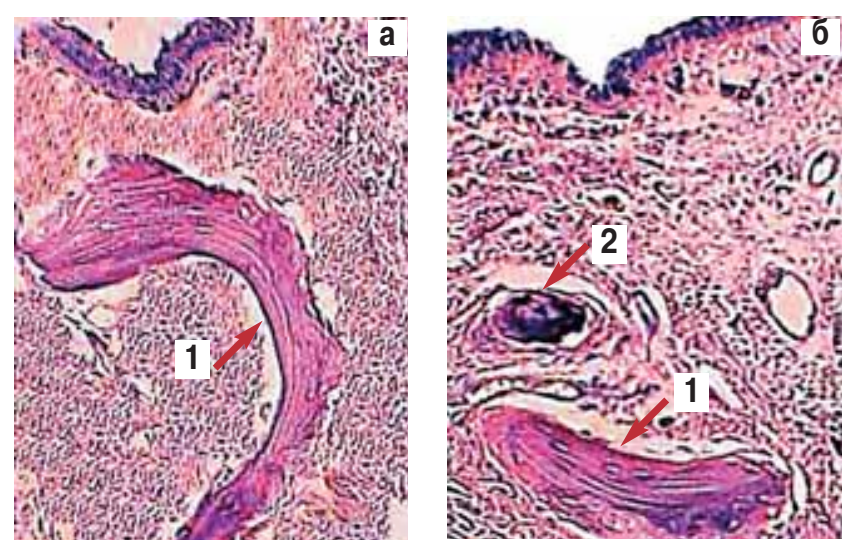

Рис. Остеохондропластическая трахеобронхопатия: а, б - очаги разрастания губчатой костной ткани (1) и обызвествления (2) в стенке бронха. Окраска гематоксилином и эозином $(\times 140)$

формированием легочного сердца и его последующей декомпенсацией. Нарастающая дыхательная недостаточность, явившаяся непосредственной причиной смерти, была обусловлена бронхообструкцией и хроническим, преимущественно интерстициальным, воспалением легких. Прижизненная трудность диагностики была связана с характерной для данной патологии скудностью клинической симптоматики и в большей мере с тяжестью состояния больной во время последнего пребывания в клинике, не позволившей выполнить бронхоскопию с получением бронхобиоптата.

\section{Литература}

1. Марга О.Я., Битуле Э.А. Хондроостеопластическая трахеобронхопатия. Грудная хир. 1974. 5: 111-112.

2. Харченко В.П., Кузьмин И.В., Алипченко Л.А. и др. Остеохондропластическая трахеобронхопатия. Арх. пат. 1995; 1: 34-39.

3. Черняев А.Л., Новиков Ю.К., Белевский А.С., Самсонова M.B. Остеохондропластическая трахеобронхопатия. Пульмонология 1994; 2: 79-81.

4. Юдин А.Л., Думанов М.А. Остеопластическая трахеобронхопатия. Диагноз с помощью КТ. Вестн. рентгенол. 1992; 2: 56-57.

5. Ashley D.J. Bony metaplasia in trachea and bronchi. J. Pathol. 1970; 102 (3): 186-188.

Поступила 02.02 .05

(c) Коллектив авторов, 2006

удк [616.231+616.233]-007.15-091 